\title{
Syntheses of CdTe Quantum Dots and Nanoparticles through Simple Sonochemical Method under Multibubble Sonoluminescence Conditions
}

\author{
Cha Hwan Hwang, Jongpil Park, Miyeon Song, Jin ho Lee, and Il-Wun Shim* \\ Department of Chemistry, Chung-Ang University, Seoul 156-756, Korea. *E-mail: iwshim@cau.ac.kr \\ Received January 19, 2011, Accepted May 13, 2011
}

\begin{abstract}
Colloidal cadmium telluride (CdTe) quantum dots (QDs) and their nanoparticles have been synthesized by one pot sonochemical reactions under multibubble sonoluminescence (MBSL) conditions, which are quite mild and facile compared to other typical high temperature solution-based methods. For a typical reaction, $\mathrm{CdCl}_{2}$ and tellurium powder with hexadecylamine and trioctylphosphine/trioctylphosphineoxide (TOP/TOPO) as a dispersant were sonicated in toluene solvent at $20 \mathrm{KHz}$ and a power of $220 \mathrm{~W}$ for $5-40 \mathrm{~min}$ at $60{ }^{\circ} \mathrm{C}$. The sizes of CdTe particles, in a very wide size range from $2 \mathrm{~nm}-30 \mu \mathrm{m}$, were controllable by varying the sonicating and thermal heating conditions. The prepared CdTe QDs show different colors from pale yellow to dark brown and corresponding photoluminescence properties due mainly to the quantum confinement effect. The CdTe nanoparticles of about $20 \mathrm{~nm}$ in average were found to have band gap of $1.53 \mathrm{eV}$, which is the most optimally matched band gap to solar spectrum.
\end{abstract}

Key Words : Cadmium telluride (CdTe), Quantum dot, Sonochemistry

\section{Introduction}

Alloyed semiconductor quantum dots (QDs) have been extensively studied owing to their versatile wide utilizations and many related researches have focused on their various tunable properties according to their particle sizes. ${ }^{1,2}$ They show different colors and photoluminescence (PL) properties as their size changes due mainly to the quantum confinement effect. ${ }^{3}$ Thus, those QDs were utilized for lightemitting diode, ${ }^{4,5}$ in vivo imaging, ${ }^{6,7}$ or absorber material of photovoltaics. $^{8-10}$ Among II-VI semiconductor QDs, CdSe or CdTe has a intense photoluminescence ${ }^{11,12}$ and so the bulk $\mathrm{CdTe}$ is used for photovoltaic energy conversion since it has a direct optical band gap of $1.44 \mathrm{eV}$ that is nearly optimally matched to solar spectrum. ${ }^{13}$ Well dispersed CdTe QDs can be deposited by spin-coating, layer-by-layer, or dip-coating methods. ${ }^{14-16}$ Most of their synthetic methods with pyrophoric organometallic precursors include $\mathrm{Cd}\left(\mathrm{CH}_{3}\right)_{2}$ as a reactant, which is harmful and dangerous to handle. ${ }^{17}$ In cases with nonpyrophoric reactants such as $\mathrm{CdO}$ or $\mathrm{Cd}(\mathrm{Ac})_{2}$, the typical reaction temperature was about $300{ }^{\circ} \mathrm{C}$ by using high boiling temperature solvents. ${ }^{18-20}$ In case of high temperature reactions, the crystal growth control was somewhat difficult because the reaction occurred rapidly. The crystal growth quenching was completed by taking aliquots of the reaction mixture during the reaction or by adding cold quenching solvent. ${ }^{18,19}$ Also, it was reported that the traditional aqueous solution route to prepare CdTe nanocrystals using thiol ligands as a capping reagent was usually very time consuming and the luminescent properties were poor in the deep red to near infrared emission window. ${ }^{11}$

For the more facile and low cost CdTe quantum dot synthesis, we adopted sonochemical method, which is convenient and simple one pot reaction without any pretreat- ments and/or high temperature condition. The sonochemical method is an application of sonoluminescence, which is a light emission phenomenon associated with the collapse of gas bubbles oscillating under an ultrasonic field. The estimated highest temperature and pressure in the liquid layer adjacent to the bubble were reported to be about 1000 ${ }^{\circ} \mathrm{C}$ and 500 bar, respectively. ${ }^{21-23}$ Also, it is noteworthy that various complex radical mechanisms were reported to be involved in many sonochemical reactions using water as a solvent, including $\mathrm{H}$ or $\mathrm{OH}$ radical formation from water molecule in their initial reaction step. ${ }^{24}$ Especially, in case of multibubblesonoluminescence(MBSL) conditions in our study, the reaction mixture was typically sonicated at 20 $\mathrm{KHz}$ and a power of $220 \mathrm{~W} .{ }^{25}$ By this process, homogenously coated materials onto various nanoparticles such as $\mathrm{TiO}_{2} /$ $\mathrm{ZnS}, \mathrm{TiO}_{2} / \mathrm{PbS}$ and $\mathrm{Cu} / \mathrm{In}_{2} \mathrm{~S}_{3}$ with a core/shell structure in nano scale were prepared in our previous research. Not only coating process but the nucleation of nanocrystals also occurred in ultrasonic field. ${ }^{26-28}$

In this study, $\mathrm{CdCl}_{2}$ and tellurium powder were used for starting materials in toluene solvent with hexadecylamine and trioctylphosphine/trioctylphosphineoxide (TOP/TOPO) as a dispersant for tellurium and product. Various CdTe quantum dots in different sizes in this sonochemical method were synthesized by varying the sonication time. Also, by heating at about $400{ }^{\circ} \mathrm{C}$ for 1 hour, the QDs were transformed into CdTe nanoparticles of about $20 \mathrm{~nm}$ range in diameter, which can be adopted for the production of inorganic dye- sensitized or quantum dots solar cells ${ }^{8,10}$ through a simple and low cost printing process.

\section{Experimental Section}

Reactant. Cadmium chloride $\left(\mathrm{CdCl}_{2}, 99.99 \%\right)$, tellurium 
powder $(99.99 \%)$, trioctylphosphine (TOP, 90\%), trioctylphosphine oxide (TOPO, 90\%), hexadecylamine (HDA, 98\%), and anhydrous toluene were purchased from Aldrich. All reagents were used without further purification.

Apparatus. An experimental apparatus for the MBSL consists of a cylindrical quartz cell into which a $5 \mathrm{~mm}$ diameter titanium horn (Misonix XL2020, USA) is inserted. The system operates at $20 \mathrm{kHz}$ and a power input of $220 \mathrm{~W}$. Continuous circulation of water to the bath in which the cell is immersed keeps the temperature of the solution inside the cell around $60{ }^{\circ} \mathrm{C}$. This reaction temperature was determined by an optimization process; below this temperature the CdTe QDs were not made or the synthetic reaction was too slow. At the higher temperature the reactions became relatively faster, but it was hard to discern their color changes arising from their crystal growth. The MBSL conditions were fixed by adjusting ultrasound intensity, solvent temperature, and distance between the horn tip and the bottom of the cell.

Synthesis. $\mathrm{CdCl}_{2}(0.093 \mathrm{~g}, 0.5 \mathrm{mmol})$, Te powder $(0.064$ g, $0.5 \mathrm{mmol})$, HDA (0.5 g), TOP/TOPO (2.5 g, 2:3 molar ratio) and toluene $9 \mathrm{~mL}$ were placed in the test cell without any thiol capping reagent. The solution in the test cell was kept at $1.4 \mathrm{~atm}$ with argon atmosphere. For the preparation of CdTe quantum dots in different sizes, the ultrasound was irradiated for 5-40 $\mathrm{min}$.

The resulting products were purified by centrifugation at $4000 \mathrm{rpm}$ for $20 \mathrm{~min}$ and the precipitates which are assumed to be unreacted materials and byproduct such as cadmium chloride, tellurium, and alkylammonium chloride salts were discarded. The dispersed QDs were precipitated with ethanol, and the supernatant was removed. The precipitated QDs were dried in vacuum for the preparation of TEM and XRD samples.

Characterization. XRD data was acquired by scanning for $50 \mathrm{~min}$ with a step size of $0.02^{\circ}$ at scan rate of $0.02^{\circ} / \mathrm{sec}$ using a Scintag XDS $2000(\mathrm{Cu} \mathrm{K} \alpha=1.54056 \AA)$. TEM images with $200 \mathrm{kV}$ accelerating voltage were acquired by the FEI Techani G2 F30 with an energy dispersive X-ray spectroscopy on carbon-coated 200 mesh copper grids. HRTEM image was obtained with a JEOL JEM-3010. Uv-vis absorption and photoluminescence (PL) spectrum were collected using Uv-vis spectrophotometer (Scinco, S-3100) and fluorescence spectrometer (Scinco, FS-2).

\section{Results and Discussion}

Figure 1 shows the typical XRD pattern of the CdTe QDs prepared by sonicating for $40 \mathrm{~min}$. at $60{ }^{\circ} \mathrm{C}$ under the described conditions, in which there are three broad peaks correspond to (111), (220), and (311) planes. They are matched quiet well with the reported CdTe peaks (JCPDS card no. 15-0770). The calculated crystallite size of QDs by the Scherrer's formula ${ }^{29}$ on the base of XRD spectra is about $10 \mathrm{~nm}$ in diameter. They are in cubic phase without any impurity such as cadmium oxide or tellurium and their crystal phase can be seen in their electron diffraction pattern shown in Figure 2(b). This result is quite interesting since

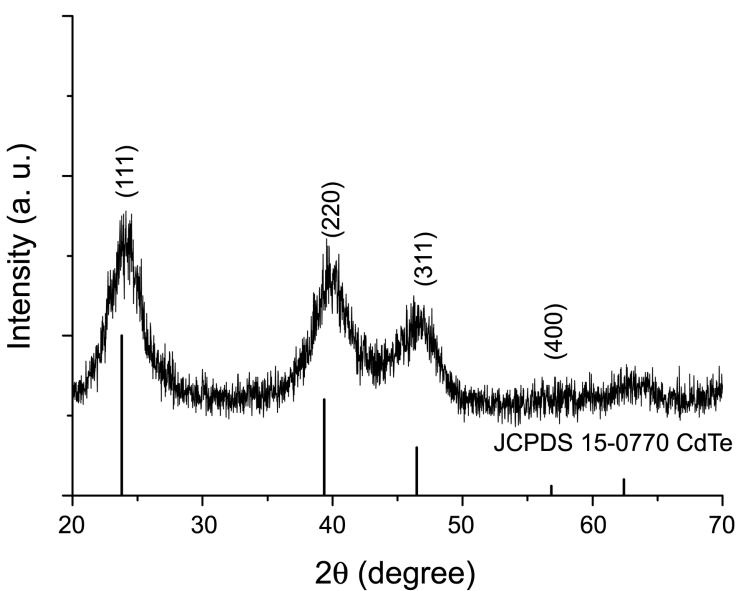

Figure 1. XRD pattern of CdTe QDs sonicated for $40 \mathrm{~min}$. at 60 ${ }^{\circ} \mathrm{C}$.

there were $\mathrm{CdO}$ and lots of unreacted $\mathrm{Te}$ as impurities when $\mathrm{CdCl}_{2}$ or $\mathrm{Cd}(\mathrm{OH})_{2}, \mathrm{NaBH}_{4}$, and Te in water were sonicated with the same sonic power for 4 hours. In order to remove the unreacted Te, the product must be heated at over $600{ }^{\circ} \mathrm{C}$ in vacuum for several hours. Also, it is noteworthy that the average size of CdTe particles prepared in above water solution process was about $30-50 \mathrm{~nm}$ in diameter, but it was uncontrollable. In addition, the HR TEM images in Figure 2. (c) and (d) show that the increase in reaction temperature from 60 to $100{ }^{\circ} \mathrm{C}$ results in an appreciable increase of the crystallinity of the CdTe QDs. But it should be mentioned that there was only a small increment in their average size from about $4.5 \mathrm{~nm}$ to about $5 \mathrm{~nm}$ as the sonication temper-
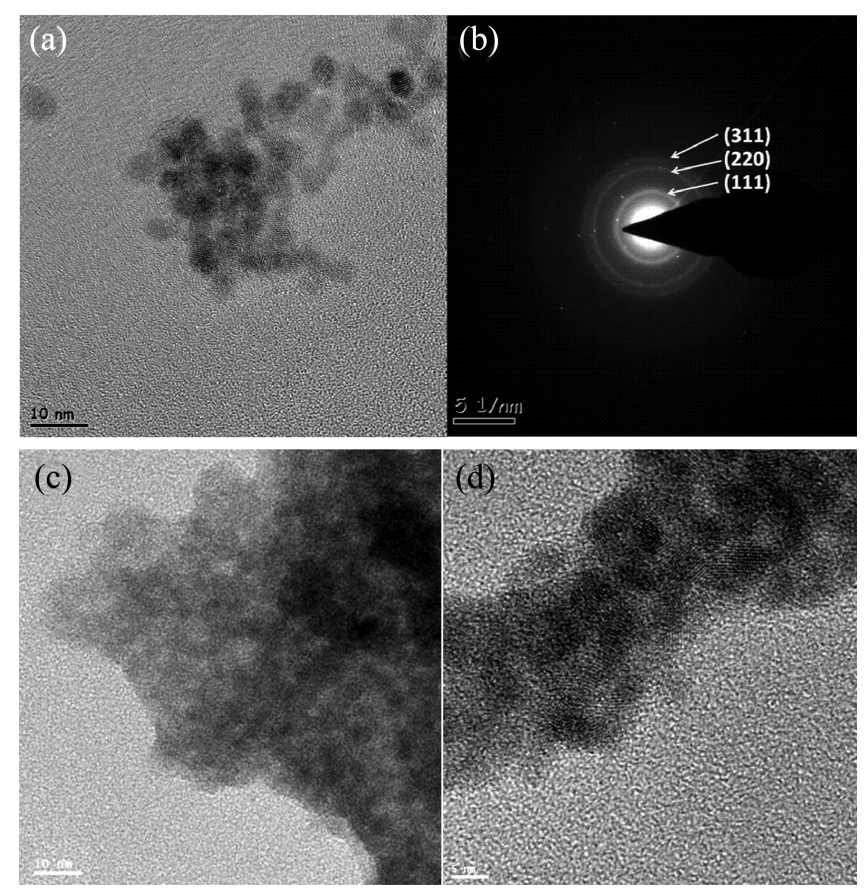

Figure 2. (a) HR-TEM image of CdTe QDs sonicated for $40 \mathrm{~min}$. at $60{ }^{\circ} \mathrm{C}$. (b) Electron diffraction pattern of CdTe QDs sonicated for $40 \mathrm{~min}$. at $60^{\circ} \mathrm{C}$. (c) HR-TEM image of CdTe QDs sonicated for 20 min. at $60^{\circ} \mathrm{C}$. (d) HR-TEM image of CdTe QDs sonicated for 20 min. at $100^{\circ} \mathrm{C}$. 


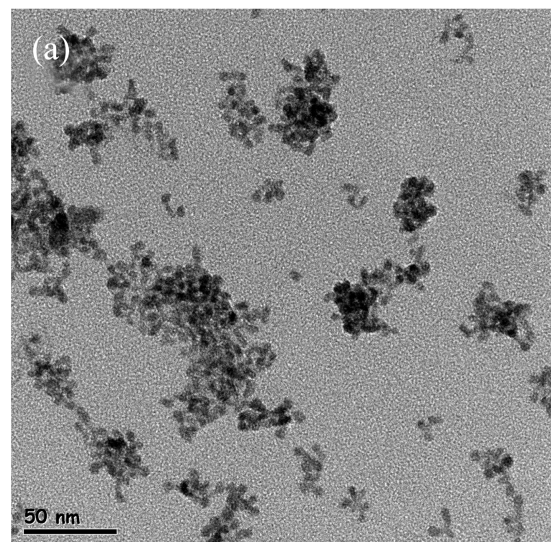

(b)

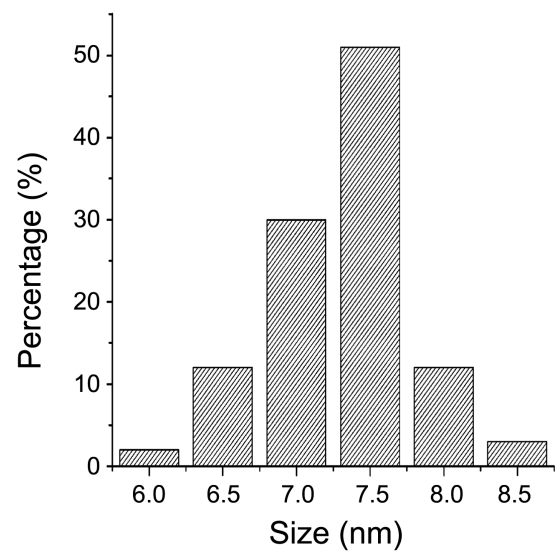

Figure 3. Image of CdTe QDs sonicated for $40 \mathrm{~min}$. at $60{ }^{\circ} \mathrm{C}$ and their size distribution.

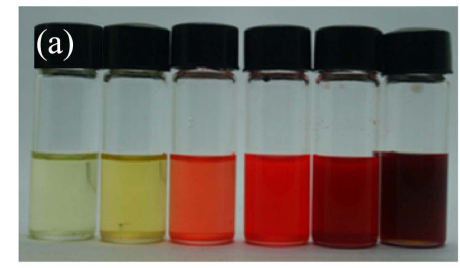

(b)

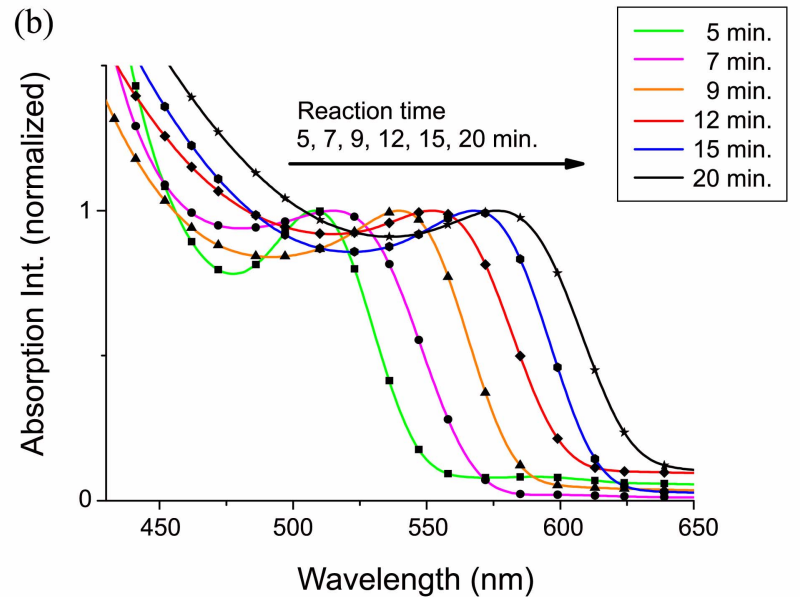

TEM image in Figure 3 illustrates the good size distribution of QDs sonicated for $40 \mathrm{~min}$. at $60{ }^{\circ} \mathrm{C}$, of which their average size is about $7-8 \mathrm{~nm}$. In this distribution, we can note that the growth of particles is occurred uniformly and the product needs no further size selecting procedure.

In a similar manner, various CdTe quantum dots in different colors were easily prepared by the aforementioned simple sonochemical reaction; in the onset of each experiment, during the initial sonication time for $2 \mathrm{~min}$, the Te slurry was completely dissolved in the solvent and the color of the solution changes to pale green, but there was no PL peak, indicating that no CdTe was made in solution at this step. Then, with further sonication for 3-18 min, the QDs were begun to be formed and the color of solutions turns from pale green to yellow and dark red as the total sonication time increases from 5 to $20 \mathrm{~min}$. After the sonication stops, there were no more color changes of the each solution. This indicates that the growth of CdTe particles is quenched.

Figure 4 shows photographs, normalized UV-vis absorption spectra, and corresponding PL spectra of the prepared colloidal CdTe quantum solutions. The color changes of the solutions from the initial pale green to yellow and dark red, shown in Figure 4(a) and (b), are assumed to arise from the increased crystal growth of CdTe quantum dots as the sonication time increases. In UV-vis spectra, 510, 520, 540, 560,575 , and $590 \mathrm{~nm}$ peaks appeared in a period of sonication time of $5,7,9,12,15$, and $20 \mathrm{~min}$, respectively. This result is quite similar to those of reports, ${ }^{11,17}$ in which there is systemic red shift of absorption peaks from the CdTe quantum dots as the crystal growth increases. Figure 4(c) and (d)

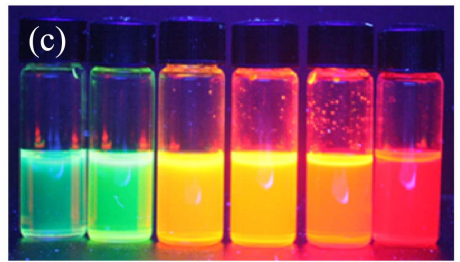

(d)

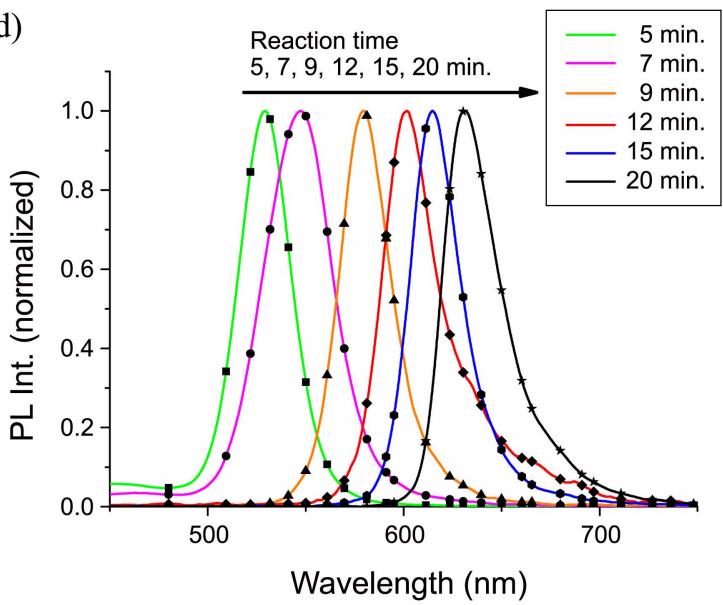

Figure 4. (a) Photographs of the colloidal CdTe solutions after different sonication time of 5, 7, 9, 12, 15, and 20 min, respectively under room light. (b) UV-vis absorption spectra of CdTe QDs prepared at different sonication time of 5-20 min. (c) Photographs of the colloidal CdTe solutions after different sonication time of 5, 7, 9, 12, 15, and $20 \mathrm{~min}$, respectively under UV lamp. (d) Photoluminescence spectra(excitation wave length: $400 \mathrm{~nm}$ ) of CdTe QDs prepared at different sonication time of 5-20 min. 


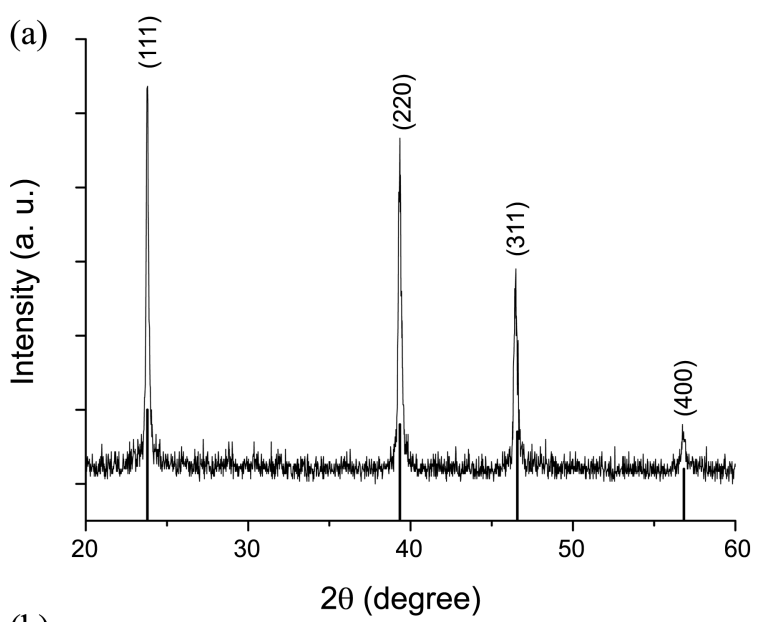

(b)

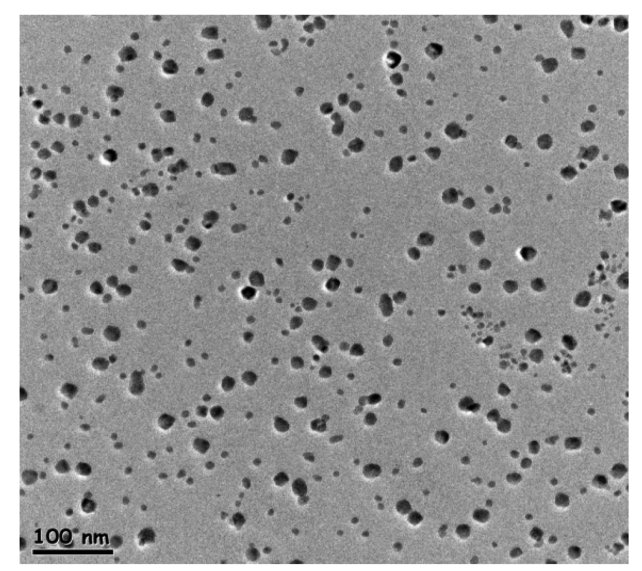

(c)

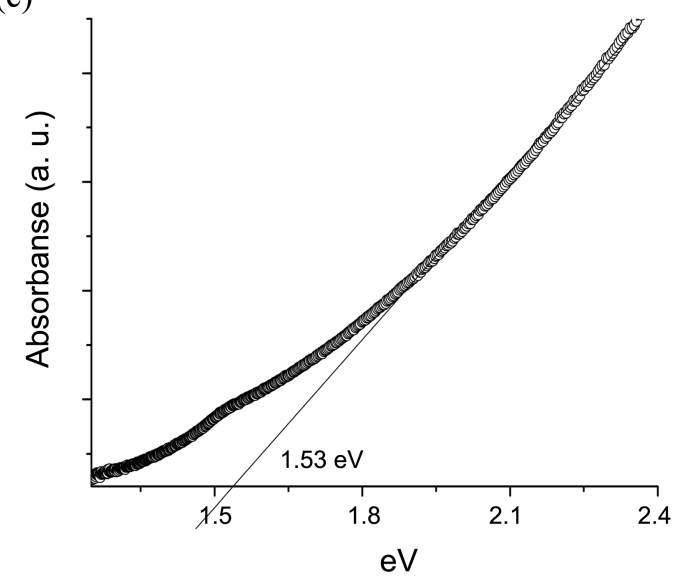

Figure 5. XRD pattern, TEM image, and band gap of CdTe particles obtained from the supernatant etanol solution after calcination at $400{ }^{\circ} \mathrm{C}, 1 \mathrm{hr}$.

shows the corresponding PL peak (the excitation wave length is $400 \mathrm{~nm}$ ) position can approach $529,547,578,601$, 614 , and $631 \mathrm{~nm}$ in a reaction time of 5, 7, 9, 12, 15 and 20 min, respectively. It should be mentioned that such sonication reaction time for the synthesis of CdTe QDs is very fast and facile in comparison to those of the traditional solution based methods for CdTe QD production. ${ }^{11,17}$ The red shift of size-dependent absorption and PL peaks is explained to be due mainly to the relatively weaker quantum confinement effect. ${ }^{11,19}$ The size of these prepared CdTe QDs with the sonication time between 5-20 min is assumed to be in around 2-4 $\mathrm{nm}$ range in diameter since their UV-vis and PL spectra are quite similar to those of the report by Wuister et al..$^{17,18}$

After CdTe QDs were precipitated with ethanol and centrifuged, the precipitate was washed with ethanol and water and dried in vacuum for $30 \mathrm{~min}$. The dark brown CdTe QD powder was calcined at $400{ }^{\circ} \mathrm{C}$ in vacuum for 1 hour. After calcinations, ethanol was added to the resulting solid and supernatant ethanol solution was separated from the precipitate by filtering. Figure 5 shows the XRD pattern, TEM image, and band gap energy of the CdTe QDs obtained from the supernatant. Their crystal phase was still in cubic, which was noted with the characteristic intense sharp peaks at $23.7^{\circ}, 39.3^{\circ}$ and $46.4^{\circ}$ corresponding to (111), (220) and (311) planes. In TEM image, particle size is in about 8-30 $\mathrm{nm}$ range, which indicates that the particles grow irregularly by solid state reaction between adjacent particles. As shown in Figure 5(c), the band gap of the calcined CdTe nanoparticles on the basis of $\mathrm{Uv}$-vis spectrophotonic data is about $1.53 \mathrm{eV}$ in comparison to $1.44 \mathrm{eV}$ of bulk CdTe. ${ }^{13,19}$ This result is quite promising since the most optimally matched band gap to solar spectrum is about $1.5 \mathrm{eV} \cdot{ }^{13}$ In addition, their EDX analysis result shows that the atomic ratio between $\mathrm{Cd}$ and $\mathrm{Te}$ is 1.08:1. In case of the precipitated CdTe particles after calcination, very similar results were obtained as above. But their TEM images show that their sizes are in a very wide range from about $1-30 \mu \mathrm{m}$ in diameter.

\section{Conclusions}

Various colloidal CdTe QDs in 2-8 nm range were successfully synthesized with a simple sonochemical reaction. Their average size was found tunable by varying the reaction conditions and the CdTe particles have uniform shape. The crystal structure of product was in cubic phase and there were no other appreciable impurities in the CdTe QDs preparation process. The color of CdTe QDs changes from pale green to yellow and to dark red due to the different sizes resulting from different sonication time. The CdTe nanoparticles in a wide size range were prepared by calcination of precipitated CdTe QDs at $400{ }^{\circ} \mathrm{C}$ for 1 hour and were also in cubic phase.

Acknowledgments. This research was supported by the Basic Science Research Program through the National Research Foundation of Korea (NRF) funded by the Ministry of Education, Science and Technology (2010-0024340) and partially by the Converging Research Center Program through the Ministry of Education, Science and Technology (2010K000969) .

\section{References}

1. Murray, C. B.; Kagan, C. R.; Bawendi, M. G. Annu. Rev. Mater. Sci. 2000, 30, 545. 
2. Goesmann, H.; Feldmann, C. Angew. Chem. Int. Ed. 2010, 49, 1362.

3. Alivisatos, A. P. J. Phys. Chem. 1996, 100, 13226.

4. Zhao, J. L.; Zhang, J. Y.; Jiang, C. Y.; Bohnenberger, J.; Basché, T.; Mews, A. J. Appl. Phys. 2004, 96, 3206.

5. Nizamoglu, S.; Ozel, T.; Sari, E.; Demir, H. V. Nanotechnology 2007, 18, 065709.

6. Mattoussi, H.; Mauro, J. M.; Goldman, E. R.; Anderson, G. P.; Sundar, V. C.; Mikulec, F. V.; Bawendi, M. G. J. Am. Chem. Soc. 2000, $122,12142$.

7. Alivisatos, P. Nature Biotechnol. 2004, 22, 47.

8. Jun, Y.-W.; Lee, J.-H.; Cheon, J. Angew. Chem. Int. Ed. 2008, 47, 5122.

9. Kongkanand, A.; Tvrdy, K.; Takechi, K.; Kuno, M.; Kamat, P. V. J. Am. Chem. Soc. 2008, 130, 4007.

10. Barea, E. M.; Shalom, M.; Giménez, S.; Hod, I.; Mora-Seró, I; Zaban A.; Bisquert, J. J. Am. Chem. Soc. 2010, 132, 6834.

11. Kang, S.; Yasuda, M.; Miyasaka, H.; Hayashi, H.; Kawasaki, M.; Umeyama, T.; Matano, Y.; Yoshida, K.; Isoda, S.; Imahori, H. ChemSusChem 2008, 1, 254.

12. Zou, L.; Gu, Z.; Zhang, N.; Zhang, Y.; Fang, Z.; Zhu, W.; Zhong, X. J. Mater. Chem. 2008, 18, 2807.

13. Rogach, A. L.; Franzl, T.; Klar, T. A.; Feldmann, J.; Gaponik, N.; Lesnyak, V.; Shavel, A.; Eychmüller, A.; Rakovich, Y. P.; Donegan, J. F. J. Phys. Chem. C 2007, 111, 14628.

14. Britt, J.; Ferekides, C. Appl. Phys. Lett. 1993, 62, 2851.

15. Luther, J. M.; Law, M.; Beard, M. C.; Song, Q.; Reese, M. O.; Ellingson, R. J.; Nozik, A. J. Nano Lett. 2008, 8, 3488.
16. Nann, T.; Ibrahim, S. K.; Woi, P.-M.; Xu, S.; Ziegler, J.; Pickett, C. J. Angew. Chem. Int. Ed. 2010, 49, 1574.

17. Konstantatos, G.; Howard, I.; Fischer, A.; Hoogland, S.; Clifford, J.; Klem, E.; Levina, L.; Sargent, E. H. Nature 2006, 442, 180.

18. Wuister, S. F.; Driel, F. V.; Meijerink, A. Phys. Chem. Chem. Phys. 2003, 5, 1253.

19. Yu, W. W.; Qu, L.; Guo, W.; Peng, X. Chem. Mater. 2003, 15, 2854.

20. Bailey, R. E.; Nie, S. J. Am. Chem. Soc. 2003, 125, 7100.

21. Hewa-Kasakarage, N. N.; Gurusinghe, N. P.; Zamkov, M. J. Phys. Chem. C 2009, 113, 4362.

22. Flint, E. B.; Suslick, K. S. Science 1991, 253, 1397.

23. Suslick, K. S. Science 1990, 247, 1439.

24. Crum, L. A.; Roy, R. A. Science 1994, 266, 233.

25. For example, see Zhu, J.; Koltypin, Y.; Gedanken, A. Chem. Mater. 2000, 12, 73.

26. Byun, K.-T.; Seo, K. W.; Shim, I.-W.; Kwak, H.-Y. Chem. Eng. J. 2008, 135, 168.

27. Lee, S. S.; Byun, K.-T.; Park, J. P.; Kim, S. K.; Lee, J. C.; Chang S.-K.; Kwak H.-Y.; Shim, I.-W. Chem. Eng. J. 2008, 139, 194.

28. Park, J. P.; Kim, S. K.; Park, J. Y.; Ahn, S.-D.; Ok, K. M.; Kwak, H.-Y.; Shim, I.-W. Thin Solid Films 2009, 517, 6663.

29. Park, J.-Y.; Park, J. P.; Hwang, C. H.; Kim, J.; Chio, M. H.; Ok, K. M.; Kwak, H.-Y.; Shim, I.-W. Bull. Korean Chem. Soc. 2009, 30, 2713.

30. Klug, H. P.; Alexander, L. E. X-ray Diffraction Procedures; John Wiley and Sons: New York, 1974. 